\title{
O PROCESSO DE REFLEXÃO ORIENTADA NA FORMAÇ̃̃O INICIAL DE UM LICENCIANDO DE QUÍMICA VISANDO O ENSINO POR INVESTIGAÇÃO E A PROMOÇÃO DA ALFABETIZAÇ̃̃O CIENTÍFICA
}

\author{
RITA DE CÁSSIA SUART - (https://orcid.org/0000-0002-1924-5353) * \\ Universidade Federal de Lavras, Lavras - MG, Brasil \\ Maria Eunice Ribeiro Marcondes - (https://orcid.org/000-0002-4099-8712) ** \\ Universidade de São Paulo, São Paulo - SP, Brasil
}

RESUMO: Esse trabalho apresenta o Processo de Reflexão Orientada (PRO) vivenciado por um licenciando de Química ao elaborar, ministrar e analisar uma sequência de aulas baseadas em uma perspectiva de ensino por investigação e para a promoção da alfabetização científica no Ensino Médio. Os resultados mostram que o licenciando evoluiu com relação às concepções apresentadas ao iniciar sua participação no processo reflexivo, utilizando referenciais teóricos sobre ensino por investigação, alfabetização científica e exigência cognitiva das questões para avaliar a sua prática docente. Os resultados também evidenciam as contribuições do Processo de Reflexão Orientada para a formação inicial docente, já que, com a orientação da pesquisadora, o licenciando pôde questionar suas ações e repensar sua prática, reconhecendo suas dificuldades, dilemas e conflitos.

Palavras-chave: Prática docente; Processo reflexivo; Atuação pedagógica.

EL PROCESO DE REFLEXIÓN ORIENTADA EN LA FORMACIÓN INICIAL DE UN LICENCIANDO EN QUÍMICA CON VISTAS A LA ENSEÑANZA POR INVESTIGACIÓN Y LA PROMOCIÓN DEL ALFABETISMO CIENTÍFICO

RESUMEN: Este trabajo presenta el Proceso de Reflexión Orientada vivido por un licenciando en Química al elaborar, ministrar y analizar una secuencia de clases basadas en una perspectiva de enseñanza por investigación y para la promoción de del alfabetismo científico en la Secundaria. Los resultados muestran que el licenciando evolucionó respeto a las concepciones presentadas al iniciar su participación en el proceso reflexivo, utilizando referenciales teóricos sobre enseñanza por investigación, alfabetismo científico y exigencia cognitiva de las

\footnotetext{
* Doutora em Ensino de Química pelo PIEC-USP. Professora Dra. Adjunta do Departamento de Química da UFLA-MG. Membro do Grupo de Pesquisa em Educação em Química (GEPEQ-IQUSP).

E-mail:<ritasuart@dqi.ufla.br >

** Doutora em Ciências. Profa. Dra do Instituto de Química da Universidade de São Paulo. Coordenadora do Grupo de Pesquisa em Educação Química (GEPEQ-IQUSP).
}

E-mail:<mermarco@iq.usp.br > 
cuestiones para evaluar su práctica docente. Los resultados también evidencian las contribuciones del Proceso de Reflexión Orientada para la formación inicial docente, una vez que, con la orientación de la investigadora, el licenciando pudo cuestionar sus acciones y repensar su práctica, reconociendo sus dificultades, dilemas y conflictos.

Palabras clave: Práctica docente; Proceso reflexive; Actuación pedagógica.

\section{THE REFLECTION-ORIENTED PROCESS IN A PRE-SERVICE CHEMISTRY TEACHER AIMING TEACHING BY INVESTIGATION AND SCIENTIFIC LITERACY PROMOTION}

ABSTRACT: This work presents the Oriented Reflection Process experienced by a pre-service chemistry teacher by elaborating, teaching and analyzing a lessons' sequence based on a teaching by investigation perspective to promote scientific literacy in high school. The results show that the pre-service teacher evolved his initial conceptions presented when he initiated his reflective process' participation, using theoretical frameworks about teaching by investigation, scientific literacy and cognitive demand of the questions to evaluate his own teaching practice. The results also highlight contributions of the Oriented Reflection Process to the pre-service teacher, since that, with academic orientation, the pre-service teacher could question his own actions and rethink his teacher practice, recognizing difficulties, dilemmas and conflicts.

Keywords: Teaching practice; Reflective process; Pedagogical proceeding. 
0 processo de reflexão orientada na formação inicial de um 1icenciando de Química visando o ensino por investigação e a promoção da alfabetização científica

\section{INTRODUÇ̃̃o}

Muitos cursos de licenciatura em Ciências ainda apresentam seus currículos baseados em concepções tradicionais e na racionalidade técnica, separando o mundo acadêmico do mundo da prática (MALDANER, 2008). Esses currículos geralmente proporcionam uma vasta gama de conhecimento específico, mas poucas vezes relacionam esses conhecimentos com aqueles necessários para a prática docente, o que pode acabar reforçando a ideia de que basta saber o conteúdo e algumas técnicas para ensinar (SILVA; SCHNETZLER, 2008; KASSEBOEHMER; FERREIRA, 2008).

As experiências vivenciadas pelos licenciandos nesses cursos podem fazer com que os futuros professores reproduzam, em seus discursos, em seus planejamentos e talvez, futuramente em suas aulas, estratégias antiquadas e pouco contribuidoras para o processo de aprendizagem dos alunos.

Abordagens e estratégias de ensino e aprendizagem que superem o ensino tradicional, pautado na transmissão de informações aos alunos e em aspectos estritamente conceituais, têm sido defendidas nos últimos anos por muitos pesquisadores e professores, de forma a promover um pensamento mais crítico nos estudantes (ZÔMPERO; LABURÚ, 2012; CARVALHO, 2006). Entre essas abordagens, destacamos o ensino por investigação. Por meio de ações estruturadas nesta abordagem, os estudantes terão a oportunidade de buscar explicações para uma situação problema norteadora, propor hipóteses e avaliar dados à luz de conhecimento científico, desenvolvendo suas habilidades cognitivas, argumentativas e aquelas relacionadas à Alfabetização Científica (AC).

Para tanto, os cursos de formação de professores de Ciências precisam oferecer condições para que os licenciandos aprendam e discutam não apenas os conteúdos específicos da disciplina, mas para que eles tenham acesso a novas metodologias de ensino e aprendizagem para que possam refletir criticamente sobre elas.

Neste contexto, o Processo de Reflexão Orientada (PRO) apresenta-se como uma nova proposta formativa que pode contribuir para uma formação mais reflexiva de professores. Nesse processo, o professor em formação inicial ou continuada, mediado por um professor mais experiente, tem a oportunidade de elaborar e reavaliar suas ideias e crenças sobre o processo de ensino e aprendizagem, suas metodologias e suas práticas de ensino (BRYAN; RECESSO, 2006).

Assim, se os licenciandos tiverem a oportunidade de desenvolverem planejamentos de ensino e de refletirem sobre os objetivos propostos, implicações e efetividade de suas ações, durante a elaboração e após a aplicação dessas atividades em sala de aula, poderão construir pensamentos mais críticos sobre o processo de ensino e de aprendizagem e sobre as suas ações pedagógicas, tornando-se mais reflexivos sobre os aspectos que contemplam a prática docente.

Neste sentido, este trabalho investiga o processo reflexivo vivenciado por um licenciando de Química, participante de ações mediadas pelo PRO, ao planejar e desenvolver uma sequência de aulas e avaliar suas ações pedagógicas, tendo em vista o ensino por investigação e a promoção da AC de estudantes do Ensino Médio. 
Rita de Cássia Suart | Maria Eunice Ribeiro Marcondes

\section{A FORMAC̣̃̃O INICIAL REFLEXIVA: VISANDO A ALFABETIZAC̣̃̃O CIENTÍFICA E 0 ENSINO PÓR INVESTIGAC̣ÃO}

Discussões bastante intensas em favor da AC têm sido realizadas por muitos especialistas e educadores nas últimas duas décadas. Para eles, o desenvolvimento da Alfabetização Científica para todos se tornou urgente e reformas educativas têm sido propostas e realizadas a fim de desenvolver habilidades e competências para alcançar tal objetivo (SHWARTZ, 2009; SASSERON; CARVALHO, 2011; BYBEE, 2006).

Pensar em AC não significa formar futuros cientistas, mas possibilitar aos alunos a compreensão de fenômenos científicos e de suas relações com os aspectos tecnológicos, sociais e ambientais envolvidos. Para o professor Ático Chassot (2003), a AC deveria ser desenvolvida para potencializar alternativas que privilegiem uma educação mais comprometida; é saber ler a linguagem que está escrita na natureza.

Nesta perspectiva, Norris e Phillips (2003) consideram que ler é um processo construtivo, pois há um pensamento cognitivo envolvido nesta ação. Ler depende de um conhecimento fundamentado do leitor, de significados que estão, muitas vezes, fora do que se lê ou do que se vivencia, o que requer uma construção ativa de novos significados e contextualização. Significa compreender, interpretar, analisar e criticar um texto ou uma ideia. Para os autores, esse é o sentido fundamental que a alfabetização científica deveria englobar. Portanto, ler envolve diversas atividades mentais essenciais para a compreensão das Ciências e cuidado maior precisa ser empreendido nesse contexto, já que a leitura das Ciências exige um conhecimento específico do conteúdo e não pode apenas estar associada ao senso comum ou ideias não fundamentadas, seja de forma científica ou relacionada a valores éticos e morais.

Neste sentido, diante das diversas transformações que nossa sociedade tem vivenciado, é importante estar alfabetizado cientificamente para compreender as potencialidades, as implicações e até mesmo, os abusos que as Ciências e os desdobramentos a ela relacionados podem gerar. A população tem importância ativa sobre decisões e discussões relacionadas aos diversos problemas que nos rodeiam e, consequentemente, sobre seus riscos, seus benefícios e sobre suas incertezas.

Para isso, o ensino de Ciências deve ser planejado para que os estudantes participem do processo de construção dos conceitos científicos e das ideias relativas à natureza das Ciências; que desenvolvam habilidades relacionadas às investigações científicas, bem como, promovam o seu posicionamento crítico e reflexivo sobre as decisões individuais e grupais, já que somos responsáveis por nossas ações e o que fazemos e decidimos impactará, de alguma forma, na sociedade como um todo. E, para que essas habilidades sejam promovidas nos estudantes, diversas estratégias e abordagens de ensino podem ser utilizadas pelos professores em suas salas de aulas. Entre elas destacamos, neste trabalho, o ensino por investigação.

$\mathrm{O}$ ensino por investigação pode possibilitar o desenvolvimento de um pensamento mais elaborado pelos estudantes, contribuindo para a promoção de habilidades de ordens superiores como a investigação de um problema, a elaboração de hipóteses, a avaliação de condições de contorno, a análise de resultados e a proposição de conclusões (ZÔMPERO; LABURÚ, 2012; CARVALHO, 2006). 
0 processo de reflexão orientada na formação inicial de um 1icenciando de Química visando o ensino por investigação e a promoção da alfabetização científica

Para Bybee (2006), o ensino por investigação precisa ser implementado para que os alunos aprendam os conceitos científicos, mas também, para que compreendam como ocorre o processo de construção do conhecimento, de forma a colocar o estudante no centro do processo de aprendizagem.

Mas, o ensino por investigação é complexo e requer a coordenação de uma série de habilidades e processos por parte dos professores (GOMES; BORGES; JUSTI, 2008). Muito mais do que dominar o conteúdo científico, o professor que deseja desenvolver uma atividade por investigação deve tornar-se um questionador, a fim de orientar o processo de ensino e aprendizagem (AZEVEDO, 2004).

No entanto, muitos professores não foram preparados para atuarem de forma investigativa em suas aulas. Muitas vezes, os professores não estão preparados para usar as metodologias investigativas, pois existe uma lacuna de conhecimento conceituale/ou compreensão incorreta ou limitada sobre a atividade por investigação, dificultando ou impedindo a proposição do ensino por investigação em suas aulas (LANGUI; NARDI, 2011; FRIEDRICHSEN; MUNFORD; ORGILL, 2006).

Ainda, desenvolver propostas investigativas torna-se mais complexo quando pensamos em um professor em formação inicial ou em início de carreira, já que ele terá de enfrentar diversas situações desconhecidas relacionadas ao ambiente escolar.

Pelo fato de concordarmos nesta pesquisa que propostas de ensino por investigação podem contribuir para o desenvolvimento de habilidades inerentes ao processo de alfabetização científica, de forma a promover nos estudantes um raciocínio mais crítico, consideramos que a formação inicial de professores deveria dar oportunidade para os licenciandos refletirem sobre suas próprias concepções, sobre os fundamentos teóricos relacionados à temática em discussão, neste caso o ensino por investigação e a alfabetização científica, bem como, possibilitar aos futuros professores elaborar e ministrar atividades inovadoras, de forma a evoluir suas concepções e melhorar as suas práticas em sala de aula, refletindo sobre elas.

Ao questionar e pensar criticamente sobre as questões que influenciam o ambiente escolar e a prática docente, os licenciandos podem começar a assumir uma nova postura questionadora e reflexiva sobre suas ações (SILVA, 2015; ALARCÃO, 2011; PEME-ARANEGA et al., 2009). Desta forma, ao se pensar em um professor reflexivo, é preciso que uma nova postura seja valorizada nos cursos de formação. Isto implica possibilitar a esses professores a elaboração de novas atividades, materiais e propostas didáticas, colocá-las em prática e realizar reflexões sucessivas acerca de sua efetividade na aprendizagem dos alunos (GAUTHIER et al., 2013: ALARCÃO, 2011; GUEDIN, 2012; PEME-ARANEGA et al., 2009).

Neste sentido, a análise e a reflexão acerca de suas próprias concepções (explícitas ou implícitas) constituem um primeiro passo para gerar nos professores, ou futuros professores, por um lado, concepções mais adequadas e, por outro, um melhoramento das práticas em sala de aula (PEME-ARANEGA et al., 2009).

Dessa forma, pesquisas em Ensino de Ciências têm utilizado a metodologia da Reflexão Orientada para mostrar que tais experiências têm influenciado a maneira pela qual o professor pensa a sua prática e, principalmente, suas crenças pessoais sobre o processo de ensino e aprendizagem (SILVA, 2015; PEME-ARANEGA et al., 2009; BRYAN; RECESSO, 2006). O Processo de Reflexão Orientada pretende, 
por meio de um processo orientado realizado por um professor mais experimente (mediador/tutor), que o professor ou futuro professor reflita sobre aspectos relacionados às suas concepções e práticas de ensino e aprendizagem.

Baseado no pressuposto que os licenciandos têm suas próprias ideias, crenças e valores, o PRO se apoia no processo de reavaliação e reelaboração dessas ideias e é caracterizada por favorecer aos professores, ambientes e contextos para descreverem e refletirem sobre suas ideias com o auxílio do mediador/tutor, oferecendo meios para ajudá-los a clarificar, confrontar e, às vezes, mudar suas teorias pessoais. Após a leitura de artigos sobre estratégias e metodologias inovadoras, elaboração de materiais, regência de aulas, por exemplo, realiza-se uma reflexão acerca das experiências vivenciadas, utilizando-se, para isso, aportes teóricos relacionados aos temas em discussão e o confronto das concepções, epistemológicas e didáticas apresentadas por eles (PEME-ARANEGA et al., 2009; ABELL; BRYAN, 1997).

Em uma de suas pesquisas, PEME-ARANEGA e colaboradores (2009) descrevem a evolução do desenvolvimento profissional de uma professora de Ciências, participante de um PRO durante cinco anos. A investigação teve início com uma fase exploratória, por meio de registros em vídeo de aulas da professora, a fim de identificar suas principais crenças explícitas. Após essa etapa, a professora participava de atividades de formação, adaptadas às suas necessidades, obstáculos e problemas práticos. Entre as ações estavam: leituras e discussões de artigos relacionados aos diversos modelos de ensino e de aprendizagem de Ciências e planejamento de unidades didáticas, as quais seriam desenvolvidas em sala de aula. Os resultados da pesquisa mostraram que as concepções explícitas e os modelos didáticos iniciais da professora eram mais avançados do que suas crenças implícitas e seus modelos práticos. Após os cinco anos de participação no PRO, houve maior concordância entre as suas crenças explícitas e implícitas e entre seus modelos didáticos declarado e prático, ambos baseados em uma perspectiva construtivista de ensino, o qual valoriza a construção do conhecimento pelos estudantes e o desenvolvimento de habilidades.

Para Abell e Bryan (1997), a reflexão orientada pode ser construída por meio de quatro contextos, que se intercomunicam e que completam um Programa de Reflexão, no qual os licenciandos terão a oportunidade de vivenciar diferentes contextos inerentes à prática docente. São eles: Contexto a. Reflexão sobre outras práticas de ensino (por meio de materiais de mídia, artigos, relatos de experiências); Contexto b. Reflexão sobre a opinião de educadores e pesquisadores (por meio de artigos, livros, entrevistas); Contexto c. Reflexão sobre si mesmo, como aprendiz. de Ciências (por meio de atividades científicas); Contexto d. Reflexão sobre sua própria prática (por meio de experiências de campo).

Os quatro contextos não são promovidos necessariamente nesta ordem, mas se comunicam durante todo o PRO, podendo proporcionar situações para que os futuros professores coloquem em ação as suas concepções, os seus conhecimentos sobre o conteúdo e sobre os saberes integradores e pedagógicos, os seus dilemas sobre a prática e a teoria, bem como, a relação entre essas duas esferas do saber.

Segundo as autoras, suas pesquisas têm demonstrado que a reflexão orientada precisa considerar o aprendizado e a reflexão dos futuros professores em contextos 
0 processo de reflexão orientada na formação inicial de um 1icenciando de Química visando o ensino por investigação e a promoção da alfabetização científica

variados. Elas argumentam que as atividades desenvolvidas pelos licenciandos durante o PRO contribuíram para eles reavaliarem suas concepções de ensino e aprendizagem e suas experiências de ensino em contextos reais de sala de aula, de forma a construírem teorias e práticas mais viáveis e de forma mais autônoma.

Portanto, concordamos que o desenvolvimento pessoal dos professores de Ciências ocorre por meio de um processo gradual de crescimento, a partir de um processo de autorregulação metacognitiva, baseado no que pensam e fazem e nos problemas reais relacionados ao ensino e aprendizagem de Ciências. Desta forma, o PRO pode gerar processos reflexivos importantes na tomada de consciência sobre os problemas e potencialidades do processo de ensino e aprendizagem, ampliando a relação "saber" - "saber fazer" (PEME-ARANEGA et al., 2008).

\section{PROCEDIMENTO METODOLÓGICO}

O presente trabalho apresenta as características de uma pesquisa qualitativa (BOGDAN; BIKLEN, 1994), baseada no PRO (ABELL; BRYAN, 1997).

O PRO apresentado neste trabalho teve duração de aproximadamente um ano e meio e se desenvolveu em momento extraclasse de um curso de licenciatura em Química de uma IES mineira, por mediação de uma das autoras do trabalho, professora formadora da Instituição. A mediadora encontrava-se afastada de suas atribuições docentes para a realização de seu doutorado, motivo pelo qual as ações do PRO foram realizadas em período extraclasse. O grupo de cinco licenciandos, uma professora de Ensino Médio da rede pública e a pesquisadora, se reuniam para discussão de temas, estratégias e práticas que almejassem um ensino por investigação e para a promoção de habilidades cognitivas e relacionadas à AC no Ensino Médio. Desde o início de sua participação no grupo, os licenciandos estavam cientes das atividades e das ações que desenvolveriam e que todas elas estavam baseadas nos pressupostos de um ensino por investigação e para a promoção da AC, como os estudos teóricos, a elaboração e aplicação de uma sequência de aulas e a análise e reflexão sobre a prática docente.

Os licenciandos que participaram do PRO estavam matriculados na segunda metade do curso e já haviam cursado algumas disciplinas relacionadas às Práticas Pedagógicas e ao Estágio Supervisionado. Embora todos os licenciandos tenham demonstrado elevada dedicação durante o PRO, neste trabalho será apresentada a participação de apenas um licenciando, denominado $\mathrm{R}$, visto que se pretende evidenciar as contribuições do percurso vivenciado pelo futuro professor, de forma a destacar a relevância de um processo formativo mais orientado, individualizado e reflexivo. A escolha por $\mathrm{R}$ está no fato de o futuro professor ter apresentado destacada participação durante os encontros reflexivos com a pesquisadora.

Durante o PRO, diversos encontros individuais e em grupo foram realizados. Os encontros em grupo tinham como objetivo contemplar os quatro contextos propostos por Abell e Bryan em um PRO. Os objetivos dos encontros estão descritos no Quadro 1. Foram realizados, ao total, 18 encontros em grupo. 
Rita de Cássia Suart| Maria Eunice Ribeiro Marcondes

Quadro 1. Objetivos dos encontros e os contextos relacionados

\begin{tabular}{|c|l|}
\hline Contexto & \multicolumn{1}{c|}{ Descrição } \\
\hline a & $\begin{array}{l}\text { Discussão de artigos para fundamentar e orientar as ações dos licenciandos } \\
\text { sobre temas relacionados às Ciências e ao ensino de Ciências por investigação } \\
\text { e para a promoção da AC. }\end{array}$ \\
\hline \multirow{6}{*}{$\mathbf{b}$} & $\begin{array}{l}\text { Apresentação, discussão e reflexão de aulas de professores experientes e } \\
\text { novatos, a fim de que avaliassem o papel do professor e dos alunos em sala } \\
\text { de aula, suas interações e os fatores que poderiam promover um ensino por } \\
\text { investigação e para a AC. }\end{array}$ \\
\hline c & $\begin{array}{l}\text { Realização de pequenas atividades, como experimentos, para discussão dos } \\
\text { resultados relacionados aos conceitos envolvidos nas atividades, para que } \\
\text { investigassem e reconhecessem seus próprios conhecimentos científicos e } \\
\text { refletissem sobre a aplicabilidade da estratégia e dos conceitos em contexto } \\
\text { real de sala de aula. }\end{array}$ \\
\hline d & $\begin{array}{l}\text { Reflexão sobre as sequências de aulas elaboradas e executadas em sala de } \\
\text { aula, bem como sobre os resultados das análises realizadas, possibilitando } \\
\text { uma reflexão sobre as potencialidades e dificuldades apresentadas na sua } \\
\text { proposição e execução. }\end{array}$ \\
\hline
\end{tabular}

Encontros individuais para reflexão sobre as atividades realizadas, as sequências de aulas propostas e as aulas ministradas, também foram realizados. Os encontros se mostraram relevantes para que cada licenciando pudesse expressar suas dúvidas, seus dilemas, suas crenças e suas dificuldades individuais, relacionadas especificamente às suas propostas. Esses encontros englobaram ações mais voltadas para o Contexto d, mas aspectos relacionados aos outros Contextos também perpassavam as reflexões, de forma a embasar e fundamentar os argumentos da pesquisadora e dos licenciandos.

As diversas atividades realizadas durante o PRO podem ser organizadas em três momentos:

1) Atividades inicias: desenvolvidas nos dois primeiros encontros do $\mathrm{PRO}$, antes da elaboração da primeira sequência de aulas pelos licenciandos e das principais discussões teóricas norteadoras das sequências. Tinham como objetivo, possibilitar a investigação das principais concepções dos licenciandos e dos elementos pedagógicos considerados ao elaborarem um plano de uma aula e uma atividade experimental para o ensino de um conceito químico escolhido por eles.

2) Elaboração da sequência de aulas: os licenciandos deveriam, individualmente, elaborar uma sequência de aulas para ser aplicada em uma escola do município da IES. As sequências deveriam contemplar os conteúdos do planejamento da escola e respeitar um número máximo de aulas disponibilizadas pela professora regente, participante do PRO, para sua posterior aplicação. Assim, embora os licenciandos tivessem autonomia para a elaboração de suas sequências, estavam limitados a algumas orientações da professora regente da escola. Todos 
0 processo de reflexão orientada na formação inicial de um 1icenciando de Química visando o ensino por investigação e a promoção da alfabetização científica

os licenciandos elaboraram uma sequência de aulas sobre determinado tema, considerando a perspectiva de um ensino por investigação e para a promoção da AC.

É importante destacar que concordamos que um ensino baseado nesta perspectiva precisa ser desenvolvido de forma dialogada, por meio de questões de diferentes exigências cognitivas. Para isso, os licenciados também tiveram acesso a discussões e reflexões sobre a relação entre o nível de exigência cognitiva das questões propostas pelos professores e das habilidades cognitivas manifestadas pelos alunos.

O processo para elaboração das sequências durou entre dois e quatro meses, dependendo do período de aplicação, número de aulas disponibilizadas, dificuldades apresentadas em sua elaboração e, ainda, interesse para sua melhor adequação. A cada reelaboração, os licenciandos enviam a proposta - também denominado plano - por correio eletrônico para a pesquisadora, a fim de a última conhecer e avaliar as ações propostas antes do encontro individual. Após essa avaliação inicial, um encontro era realizado entre pesquisadora e cada licenciando para que sugestões, modificações ou permanência das ideias para a reelaboração das propostas seguintes fossem apontadas, discutidas e refletidas. Cada licenciando participou de, no mínimo, cinco encontros para essa finalidade. O licenciando R, investigado nesta pesquisa, participou de nove encontros para a elaboração de sua sequência.

3) Reflexão sobre a prática: Análise dos planos propostos e das aulas ministradas: Os planos propostos e as aulas ministradas foram analisadas, inicialmente, de forma individual pelos licenciandos. Após encaminhar as análises para a pesquisadora, encontros reflexivos entre cada um deles e a pesquisadora foram realizados. As análises dos diversos planos elaborados e das aulas ministradas permitiram aos licenciandos compreenderem com maior profundidade os níveis investigativo e de $\mathrm{AC}$ planejados e alcançados e a demanda cognitiva que as questões planejadas e propostas solicitavam. A reflexão sobre a prática possibilitou aos licenciandos problematizar as situações vivenciadas, questionar e autoquestionar o que se pensou fazer, o que se fez e o que poderia ser feito. É importante destacar que em um momento posterior, todos os licenciandos envolvidos no PRO analisaram as ações propostas e realizadas uns pelos outros. No entanto, embora bastante rica e relevante, essa discussão não será realizada neste trabalho, devido ao seu foco e limitação de espaço. O licenciando R participou de sete encontros para refletir sobre a sua prática.

Todos os encontros individuais entre a pesquisadora e o licenciando R, bem como os encontros em grupo, foram gravados em áudio e vídeo e, posteriormente, transcritos para a análise. Neste trabalho foram utilizadas apenas as gravações dos encontros individuais entre pesquisadora e licenciando $\mathrm{R}$.

Pesquisadora e licenciandos utilizaram os elementos e critérios apresentados nos quadros 2, 3 e 4 para analisar as sequências elaboradas e as aulas ministradas.

- Nível Investigativo das sequências de aulas elaboradas e das aulas ministradas: $\mathrm{O}$ Quadro 2 mostra os elementos pedagógicos considerados essenciais para uma atividade ser considerada investigativa e a característica de cada um dos elementos segundo o nível de investigação (SILVA, 2011). ${ }^{1}$ 
Quadro 2. Categorias adaptadas de Silva (2011) para a abordagem investigativa

\begin{tabular}{|c|c|c|c|c|}
\hline & \multicolumn{4}{|c|}{ NÍVEL INVESTIGATIVO } \\
\hline $\begin{array}{l}\text { ELEMENTOS } \\
\text { PEDAGÓGICOS }\end{array}$ & $\begin{array}{c}\text { NÃO APRESENTA } \\
\text { CARACTERÍSTICAS } \\
\text { INVESTIGATIVAS } \\
\text { C1 }\end{array}$ & $\begin{array}{c}\text { TANGENCIA } \\
\text { CARACTERÍSTICAS } \\
\text { INVESTIGATIVAS } \\
\text { C2 }\end{array}$ & $\begin{array}{c}\text { APRESENTA } \\
\text { ALGUMAS } \\
\text { CARACTERÍSTICAS } \\
\text { INVESTIGATIVAS } \\
\text { C3 }\end{array}$ & $\begin{array}{c}\text { ATIVIDADE } \\
\text { INVESTIGATIVA } \\
\text { C4 }\end{array}$ \\
\hline $\begin{array}{l}\text { Levantamento } \\
\text { das concepções } \\
\text { dos alunos }\end{array}$ & Não apresenta & $\begin{array}{l}\text { A partir de } \\
\text { questões } \\
\text { genéricas ou } \\
\text { conceituais }\end{array}$ & $\begin{array}{c}\text { A partir de } \\
\text { questões } \\
\text { contextualizadas } \\
\text { em relação ao } \\
\text { assunto e ao } \\
\text { cotidiano do } \\
\text { aluno }\end{array}$ & $\begin{array}{c}\text { Pertinente } \\
\text { ao assunto, } \\
\text { contextualizado } \\
\text { com a realidade } \\
\text { do aluno }\end{array}$ \\
\hline Problematização: & Não apresenta & $\begin{array}{l}\text { Apresentação de } \\
\text { perguntas sobre } \\
\text { o conteúdo, } \\
\text { que podem ser } \\
\text { respondidas } \\
\text { consultando o } \\
\text { livro didático, por } \\
\text { exemplo }\end{array}$ & $\begin{array}{c}\text { Apresenta } \\
\text { questões } \\
\text { para serem } \\
\text { investigadas } \\
\text { e estão } \\
\text { relacionadas ao } \\
\text { tema }\end{array}$ & $\begin{array}{l}\text { Um problema } \\
\text { bem delineado, } \\
\text { cujas respostas } \\
\text { poderão ser } \\
\text { alcançadas } \\
\text { por meio da } \\
\text { realização de } \\
\text { uma atividade, } \\
\text { busca de } \\
\text { informações e } \\
\text { discussão }\end{array}$ \\
\hline $\begin{array}{c}\text { Atividade } \\
\text { Experimental }\end{array}$ & $\begin{array}{l}\text { Atividade por } \\
\text { demonstração, } \\
\text { onde o aluno } \\
\text { observa o que } \\
\text { o professor } \\
\text { apresenta, sem } \\
\text { participar }\end{array}$ & $\begin{array}{c}\text { Por } \\
\text { demonstração } \\
\text { pelo professor } \\
\text { ou por realização } \\
\text { dos alunos, a } \\
\text { partir de um } \\
\text { procedimento } \\
\text { dado }\end{array}$ & $\begin{array}{c}\text { Realizado pelo } \\
\text { professor ou } \\
\text { pelos alunos, } \\
\text { a partir de um } \\
\text { procedimento } \\
\text { inicial, } \\
\text { completado pelo } \\
\text { aluno. }\end{array}$ & $\begin{array}{l}\text { Realizado pelos } \\
\text { alunos, a partir } \\
\text { de um roteiro } \\
\text { previamente } \\
\text { acordado, } \\
\text { onde os dados } \\
\text { são obtidos e } \\
\text { analisados pelos } \\
\text { estudantes }\end{array}$ \\
\hline $\begin{array}{c}\text { Questões para } \\
\text { os alunos }\end{array}$ & $\begin{array}{c}\text { Não exploram } \\
\text { conceitualmente } \\
\text { os dados obtidos } \\
\text { na atividade e } \\
\text { nas aulas }\end{array}$ & $\begin{array}{l}\text { Exploram } \\
\text { parcialmente os } \\
\text { dados obtidos, } \\
\text { sem solicitação } \\
\text { de conclusões }\end{array}$ & $\begin{array}{l}\text { Exploram os } \\
\text { dados obtidos, } \\
\text { com solicitação } \\
\text { de conclusões }\end{array}$ & $\begin{array}{c}\text { Exploram os } \\
\text { dados obtidos, } \\
\text { com solicitação } \\
\text { de conclusões e } \\
\text { aplicação a novas } \\
\text { situações }\end{array}$ \\
\hline
\end{tabular}

- Nível cognitivo das questões propostas: Todas as questões propostas nas sequências e nas aulas ministradas foram analisadas de acordo com as categorias propostas a seguir, no Quadro 3. 
0 processo de reflexão orientada na formação inicial de um 1icenciando de Química visando o ensino por investigação e a promoção da alfabetização científica

Quadro 3. Categorias para a exigência cognitiva das questões

\begin{tabular}{|c|l|}
\hline Nível & \multicolumn{1}{c|}{ Descrição } \\
\hline P1 & $\begin{array}{l}\text { Requer que o estudante somente recorde uma informação partindo dos } \\
\text { dados obtidos. }\end{array}$ \\
\hline P2 & $\begin{array}{l}\text { Requer que o estudante desenvolva atividades como sequenciar, comparar, } \\
\text { contrastar, aplicar leis e conceitos para a resolução do problema. }\end{array}$ \\
\hline P3 & $\begin{array}{l}\text { Requer que o estudante utilize os dados obtidos para propor hipóteses, fazer } \\
\text { inferências, avaliar condições e generalizar. }\end{array}$ \\
\hline
\end{tabular}

- Nível de alfabetização científica: Para analisar o nível de AC proposto e alcançado nas sequências elaboradas e nas aulas ministradas, foram utilizadas as dimensões propostas por Shwartz (2009), evidenciadas no Quadro 4.

Quadro 4. Dimensões de AC propostas por Shwartz (2009, p. 71)

\begin{tabular}{|c|c|}
\hline Dimensão & \multicolumn{1}{c|}{ Descrição } \\
\hline $\begin{array}{c}\text { Conhecimento } \\
\text { científico da química } \\
\text { e dos conteúdos da } \\
\text { química - Conteúdo }\end{array}$ & $\begin{array}{l}\text { Ideias gerais das ciências, como a química como uma disciplina, } \\
\text { uma ciência que conduz investigações, que explica fenômenos, } \\
\text { características da química, como as explicações macroscópicas, } \\
\text { a energia envolvida nas reaços e a sua linguagem específica. }\end{array}$ \\
\hline Química no Contexto & $\begin{array}{l}\text { Uma pessoa quimicamente alfabetizada deve ser apta a: explicar } \\
\text { os fenômenos do cotidiano, usar os conhecimentos químicos no } \\
\text { seu dia a dia, como um consumidor de produtos e tecnologias. }\end{array}$ \\
\hline $\begin{array}{c}\text { Habilidades de } \\
\text { aprendizagem de alta } \\
\text { ordem }\end{array}$ & $\begin{array}{l}\text { Uma pessoa quimicamente alfabetizada é capaz de levantar } \\
\text { questões e procurar informações quando necessário, analisando } \\
\text { os pontos positivos e negativos em um debate científico. }\end{array}$ \\
\hline Aspectos afetivos & $\begin{array}{l}\text { A pessoa quimicamente alfabetizada tem uma visão imparcial } \\
\text { e realista da química e de suas implicações. Esta pessoa } \\
\text { demonstra interesse em assuntos químicos através de outros } \\
\text { meios, além do escolar, como a televisão. }\end{array}$ \\
\hline
\end{tabular}

As análises e discussões dos resultados serão apresentadas a seguir, considerando a seguinte ordem: análises das atividades iniciais realizadas pelo licenciando R; análises relacionadas ao processo de reelaboração de seus seis planos, sob orientação da pesquisadora; análise das sete aulas ministradas por ele. Ressalta-se que as análises dos planos elaborados e das aulas ministradas estão baseadas nos níveis cognitivos das questões propostas, nos níveis de investigação dos elementos pedagógicos (levantamento das concepções dos alunos, problematização, atividade experimental e questões para os alunos) e níveis de AC, conforme apresentados anteriormente. Todo o processo de reflexão realizado entre licenciando e pesquisadora será evidenciado por meio de excertos das transcrições dos encontros reflexivos, de forma a evidenciar as contribuições do PRO para a formação reflexiva do licenciando. 
A pesquisa está registrada no Conselho de Ética de Pesquisa da IES e todos os dados coletados e aqui utilizados foram autorizados para pesquisa e publicação por seus envolvidos, ou seja, pelos licenciandos e pelos pais ou responsáveis dos estudantes do Ensino Médio da escola parceira.

\section{DISCUSSÃO DOS RESULTADOS}

\section{A PARTICIPAÇÃO DO LICENCIANDO R NO PRO}

Conforme apresentado na metodologia, ao iniciar o PRO o licenciando $\mathrm{R}$ participou da elaboração de algumas atividades que possibilitaram a ele refletir sobre suas concepções, bem como, à pesquisadora, reconhecê-las. A Figura 1 representa as ideias manifestadas por ele durante sua participação nessas atividades, bem como, a relação dessas ideias com a perspectiva norteadora deste PRO, ou seja, um processo de ensino visando a alfabetização científica por meio do ensino por investigação.

Observa-se que as ideias iniciais do licenciando $\mathrm{R}$ distanciam-se das concepções norteadoras deste PRO. Ele apresenta, por exemplo, dificuldades para a proposição de uma atividade experimental com características investigativas; não considera o trabalho em grupo e a contextualização e, ainda, não propõe uma questão ou uma problematização em suas atividades.

Figura 1. Esquema representativo das ideias iniciais manifestadas pelo licenciando $R$

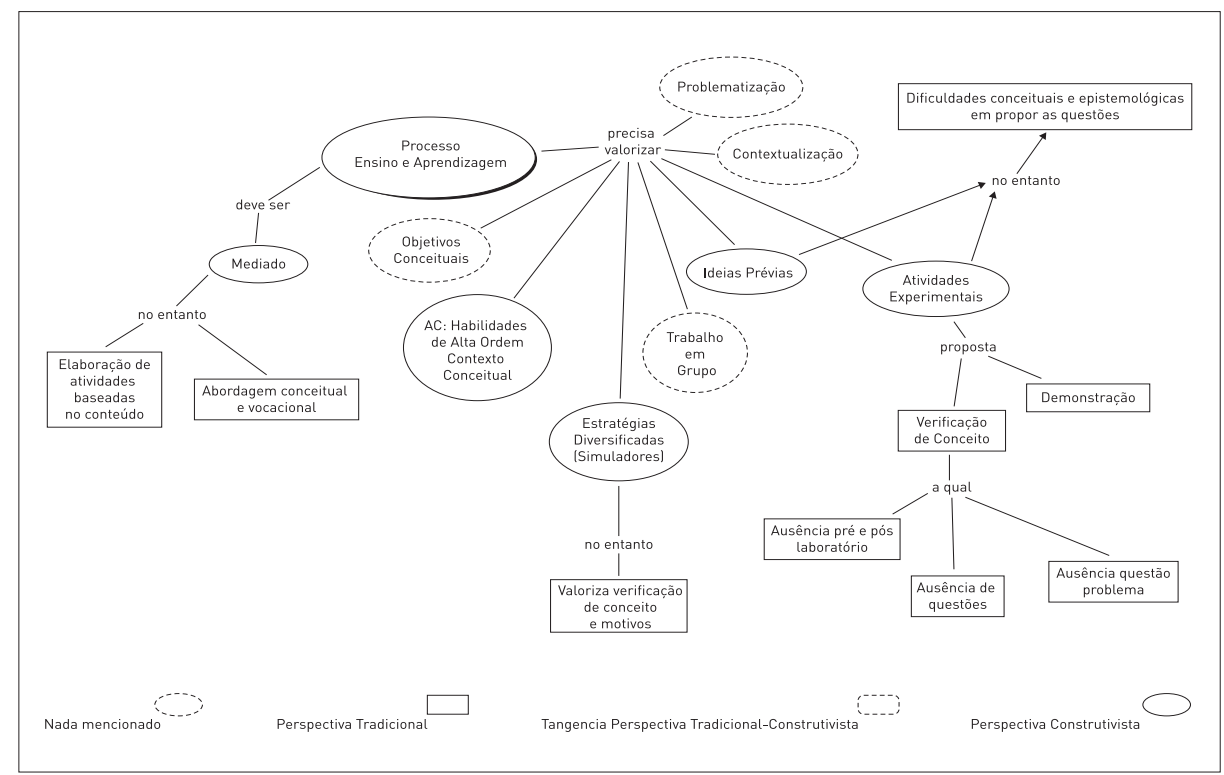

Por exemplo, o experimento proposto pelo licenciando se referia à determinação de oxigênio dissolvido na água, com o objetivo de tratar conceitos como reação química, cálculo estequiométrico e oxirredução, por meio da análise 
0 processo de reflexão orientada na formação inicial de um 1icenciando de Química visando o ensino por investigação e a promoção da alfabetização científica

quantitativa da massa de $\mathrm{O}_{2}$ presente em uma palha de aço imersa em uma amostra de água. Mas, a descrição do experimento apresentada por $\mathrm{R}$ se limitava a aspectos conceituais, não destacando habilidades que poderiam ser desenvolvidas pelo envolvimento ativo dos alunos na realização da atividade. O licenciando não apresentou uma questão problema, questões para serem respondidas pelos alunos ou um objetivo para a atividade. Assim, ao não propor o desenvolvimento de habilidades cognitivas ou relacionadas à investigação, o experimento poderia apenas apresentar características de uma atividade para verificação de conceitos. Alguns desses aspectos são discutidos durante o encontro individual reflexivo, evidenciados no Quadro 5 a seguir. Por meio da mediação da pesquisadora (P), a ausência da questão problema é percebida pelo licenciando e ele reconhece que sua proposta ainda apresenta lacunas para ser considerada uma atividade por investigação.

Quadro 5. Reflexão entre Pesquisadora e Licenciando sobre o experimento

\begin{tabular}{|c|l|}
\hline $\mathbf{L}$ & \multicolumn{1}{c|}{ Descrição das falas } \\
\hline $\mathbf{P}$ & Eo experimento? É um bom experimento? («licenciando lendo)) \\
\hline $\mathbf{R}$ & Acho que do jeito que eu coloquei é mais tradicional \\
\hline $\mathbf{P}$ & Tradicional... por quê? \\
\hline $\mathbf{R}$ & $\begin{array}{l}\text { Os alunos vão determinar a quantidade de oxigênio e ele vai ter esse resultado, esse } \\
\text { determinado...acho que não dá para...não dá para o aluno propor hipóteses...acho que } \\
\text { é mais tradicional }\end{array}$ \\
\hline $\mathbf{P}$ & $\begin{array}{l}\text { Para ser um experimento investigativo tem um item essencial ((Aluno pensa)) } \\
\text { Para investigar alguma coisa... o que você tem que ter para investigar? A questão } \\
\text { problema... Tem questão problema? }\end{array}$ \\
\hline $\mathbf{R}$ & \begin{tabular}{l} 
((Risos) Não tem \\
\hline
\end{tabular} \\
\hline
\end{tabular}

Após esse momento inicial de reflexão sobre as concepções dos licenciandos, a pesquisadora inicia os encontros em grupo para discussões sobre os principais aspectos que norteariam as ações propostas no PRO. Assim, por meio de estudo de textos norteadores do ensino por investigação e para a promoção da AC, bem como, por meio das reflexões realizadas em grupo e individuais com a pesquisadora, o licenciando R teve a oportunidade de reelaborar suas concepções, as quais ainda se demonstravam insuficientes para o desenvolvimento de um ensino por investigação e para a promoção da $\mathrm{AC}$, nas primeiras atividades. Então, o licenciando R inicia a elaboração de sua proposta de sequência de aulas para ser desenvolvida na escola.

O Quadro 6 apresenta a síntese dos aspetos analisados nos planos elaborados por R. Como poucas alterações ocorreram entre a reelaboração dos planos 2 e 3, e, entre os planos 4, 5 e 6, as análises estão apresentadas de forma agrupada. 
Rita de Cássia Suart| Maria Eunice Ribeiro Marcondes

Quadro 6. Síntese dos aspectos analisados nos planos apresentados pelo licenciando

\begin{tabular}{|c|c|c|c|}
\hline Aspecto Investigado & Plano 1 & Plano 2 e 3 & Planos 4, 5 e 6 \\
\hline $\begin{array}{c}\text { Nível investigativo } \\
\text { predominante-plano }\end{array}$ & $\begin{array}{c}\text { Tangência } \\
\text { características } \\
\text { investigativas } \\
\text { (C2) }\end{array}$ & $\begin{array}{c}\text { Algumas } \\
\text { características } \\
\text { investigativas } \\
\text { (C2/C3) }\end{array}$ & $\begin{array}{c}\text { Algumas } \\
\text { características } \\
\text { investigativas/ } \\
\text { investigativo } \\
\text { (C3/C4) }\end{array}$ \\
\hline $\begin{array}{c}\text { Nível Cognitivo } \\
\text { predominante }\end{array}$ & P1, P2 e P3 & P1 e P2 & P1, P2 e P3 \\
\hline $\begin{array}{c}\text { Nível/Dimensão } \\
\text { predominante } \\
\text { de AC }\end{array}$ & $\begin{array}{c}\text { Conteúdo e } \\
\text { Contexto }\end{array}$ & $\begin{array}{c}\text { Conteúdo e } \\
\text { Contexto }\end{array}$ & $\begin{array}{c}\text { Conteúdo, Contexto, } \\
\text { Habilidades de } \\
\text { Alta Ordem e } \\
\text { Aspectos Afetivos }\end{array}$ \\
\hline
\end{tabular}

Os planos elaborados a partir da temática Corantes, para o desenvolvimento de conceitos como solubilidade e polaridade de compostos orgânicos, foram reelaborados seis vezes pelo licenciado R. Encontros foram realizados, entre pesquisadora e licenciando, a cada nova reelaboração. O Plano 6 foi o aplicado em sala de aula.

Durante os encontros individuais, reflexões relacionadas à forma de questionar e mediar os alunos sempre surgiam. Percebe-se, por exemplo, a evolução dos níveis cognitivos das questões para serem propostas em aula. Embora apresente poucas questões, desde o primeiro plano, no Plano 4 ele já consegue propor uma maior relação dos conteúdos e das habilidades que poderiam ser desenvolvidas pelos alunos, já que as questões passam a contemplar os vários níveis cognitivos. O Quadro 7 evidencia a evolução do licenciando na proposição de questões para os seus planos.

Quadro 7. Nível Cognitivo das questões propostas pelo licenciando $R$

\begin{tabular}{|c|c|c|c|}
\hline \multicolumn{4}{|c|}{ Número de questões e nível cognitivo } \\
\hline Planos & P1 & P2 & P3 \\
\hline Plano 1 & 4 & 3 & 3 \\
\hline Plano 2 & -- & 1 & 2 \\
\hline Plano 3 & -- & 1 & 2 \\
\hline Planos 4, 5 e 6 & 11 & 11 & 5 \\
\hline
\end{tabular}

Percebe-se que, nos primeiros planos, o licenciando elabora poucas questões, as quais são, na maioria, de elevada exigência cognitiva. Embora exigir cognitivamente do estudante seja de extrema relevância para seu desenvolvimento conceitual e argumentativo, questões de menor exigência cognitiva também se revelam de extrema importância, pois podem auxiliar os alunos a organizar suas ideias, caminhando de um nível de menor para maior demanda de abstração e complexidade (CHAMIZO; HERNANDEZ, 2000; ZOLLER; DORI; LUBEZKY, 2002). As questões de nível P3 exigem dos estudantes raciocínios de ordens superiores, como fazer inferências e 
0 processo de reflexão orientada na formação inicial de um 1icenciando de Química visando o ensino por investigação e a promoção da alfabetização científica

avaliar condições como, por exemplo, as questões que indagam sobre o "Por quê", já que exigem dos estudantes a utilização e relação de conhecimentos estabelecidos (CHAMIZO; HERNADEZ, 2000; ZOLLER; DORI; LUBEZKY, 2002). Assim, conforme os planos vão sendo reelaborados, o licenciando passa a valorizar questões dos três níveis de exigência cognitiva e, no último plano, passa a contemplar questões de todos os níveis cognitivos. Alguns exemplos de questões propostas estão destacados a seguir, no Quadro 8:

Quadro 8. Exemplos de questões propostas pelo licenciando $\mathrm{R}$ e seu respectivo Nível Cognitivo

\begin{tabular}{|l|c|}
\hline \multicolumn{1}{|c|}{ Questão } & Nível Cognitivo \\
\hline O que é um corante? & P1 \\
\hline $\begin{array}{l}\text { Como você agruparia os corantes de acordo com a interação com os } \\
\text { adsorventes utilizados? }\end{array}$ & P3 \\
\hline $\begin{array}{l}\text { De acordo suas hipóteses e com base nos resultados obtidos no } \\
\text { experimento, proponha uma explicação para os fenômenos ocorridos no } \\
\text { experimento. }\end{array}$ & \\
\hline
\end{tabular}

Ainda é importante considerar que a proposição de novas questões propicia maior possibilidade de os alunos participarem da análise dos resultados, elaboração de conclusões e respostas à questão problema inicial, evidenciando uma evolução dos planos, inicialmente classificados no nível investigativo C2, onde a questão problema e o levantamento das ideias prévias priorizavam questões conceituais, para os níveis C3 e C4, nos últimos planos, os quais evidenciam questões para serem investigadas e relacionadas ao contexto dos estudantes.

O quadro 9 a seguir evidencia a evolução dos níveis investigativos dos elementos pedagógicos presentes dos planos de R. Na primeira aula do primeiro plano, por exemplo, o professor em formação inicial sugere o levantamento de ideias prévias (Cita-Quadro 9), evidenciando o seu reconhecimento sobre a importância desse elemento pedagógico para a proposta. No entanto, não apresenta as questões que poderiam ser utilizadas.

Quadro 9. Nível Cognitivo dos elementos pedagógicos presente nos planos

\begin{tabular}{|c|c|c|c|c|}
\hline \multicolumn{5}{|c|}{ Elementos Pedagógicos e Níveis Cognitivos } \\
\hline Planos & $\begin{array}{c}\text { Levantamento } \\
\text { Ideias }\end{array}$ & Problematização & Experimento & $\begin{array}{c}\text { Questões para } \\
\text { alunos }\end{array}$ \\
\hline Plano 1 & Cita & C2 & C2 & C3 \\
\hline Planos 2,3 & C2/C3 & C3 & C2 & C3 \\
\hline Planos 4, 5 e 6 & C3 & C3 & C2 & C4 \\
\hline
\end{tabular}

Em um dos encontros individuais ele comenta que ainda apresentava dúvidas sobre a estratégia que utilizaria, se um questionário, desenho ou outro 
instrumento. Conforme os encontros reflexivos acontecem, ele reelabora o seu plano e na primeira aula do segundo plano sugere o levantamento de questões prévias, problematizando o tema através da questão problema, juntamente com uma imagem de um rio poluído por corantes. Para auxiliar a identificação das ideias prévias, ele sugere solicitar aos alunos a elaboração de um texto. A pesquisadora questiona o que ele pretende com o texto e se o material traria orientações aos estudantes para sua elaboração ou seria livre para os alunos descreverem o que considerassem necessário. O Quadro 10 mostra a transcrição do encontro individual evidenciando a reflexão:

Quadro 10. Reflexão entre Pesquisadora e Licenciando sobre o levantamento das ideias

\begin{tabular}{|c|c|}
\hline $\mathbf{L}$ & Descrição das falas \\
\hline $\mathbf{R}$ & $\begin{array}{l}\text { Então... eu tinha pensado em deixar um textinho em cima da folha para clarear um } \\
\text { pouco e, também, ir discutindo com eles, fazendo uma conversa inicial. }\end{array}$ \\
\hline $\mathbf{P}$ & $\begin{array}{l}\text { Essa conversa inicial, baseada nas ideias. Você vai colocar um texto inicial e uma } \\
\text { questão problema... aí você vai mostrar as fotos...tá e aí? }\end{array}$ \\
\hline $\mathbf{R}$ & $\begin{array}{l}\text { Aí com o que for surgindo de ideias, anotar no quadro as ideias e deixar que eles } \\
\text { escrevessem. }\end{array}$ \\
\hline $\mathbf{P}$ & $\begin{array}{l}\text { Mas é importante que a gente retome o texto...não sei se você voltou em algum } \\
\text { momento nas ideias do texto }\end{array}$ \\
\hline $\mathbf{R}$ & Não \\
\hline $\mathbf{P}$ & $\begin{array}{l}\text { Senão o questionário vai ficar...ficaria lá e não voltaria...então, a gente tem que lembrar } \\
\text { de retomar essas ideias e voltar com os alunos... para que ocorra aquele crescimento } \\
\text { cognitivo gradativo. }\end{array}$ \\
\hline
\end{tabular}

Observa-se certa dificuldade de o licenciando propor o levantamento das ideias dos alunos, bem como, considerar a importância de tratar em sala de aula as principais concepções manifestadas pelos estudantes. Embora o licenciando proponha o levantamento das ideias, a sua proposta apresenta-se genérica, não nos permitindo compreender com clareza o que seria promovido e como as ideias seriam utilizadas, ou seja, ele apenas cita a utilização da estratégia. A pesquisadora, inclusive, atenta ao licenciando quanto à importância de voltar às ideias que foram manifestadas por meio do instrumento nas próximas aulas. Segundo Mellado (1998), professores em formação inicial fazem planejamentos considerando as ideias prévias dos alunos, mas, muitas vezes, sua compreensão epistemológica se restringe a citar a utilização dessas, acabando por esquecê-las ou ignorá-las, sem realizar um tratamento avaliativo.

Utilizando das ideias e reflexões ocorridas no encontro anterior, o licenciando repensa sobre o levantamento de ideias dos alunos e utilizando como estratégia a redação, apresenta orientações de elaboração para os alunos, no plano 3. Assim, esse elemento foi classificado no nível C3, já que apresentava uma 
0 processo de reflexão orientada na formação inicial de um 1icenciando de Química visando o ensino por investigação e a promoção da alfabetização científica

questão contextualizada e relacionada ao tema de estudo. Ele descreve que utilizará os textos produzidos pelos alunos para averiguar as concepções manifestadas para posterior discussão em sala de aula, demonstrando preocupação com o tratamento das ideias prévias.

Esse percurso evidencia a importância do PRO durante a elaboração dos planos, já que pesquisadora e licenciando haviam refletido, em encontros anteriores, sobre a importância de se tratar as ideias dos alunos durante as aulas e não apenas levantá-las, sem um propósito maior. Mas, na perspectiva de desenvolver um instrumento mais instigante no último plano, o licenciando argumenta, durante o encontro individual com a pesquisadora, que pretendia elaborar uma história em quadrinhos para realizar o levantamento das ideias iniciais, ao contrário de utilizar o texto proposto inicialmente, como mostra o trecho descrito no Quadro11.

Quadro 11. Reflexão entre Pesquisadora e Licenciando sobre a reelaboração do instrumento

\begin{tabular}{|c|l|}
\hline $\mathbf{L}$ & \multicolumn{1}{c|}{ Descrição das falas } \\
\hline $\mathbf{P}$ & Está tudo certo? \\
\hline $\mathbf{R}$ & $\begin{array}{l}\text { Está ...só tem uma coisa agora (risos)... Então.......] deixar em formato de história para } \\
\text { envolver mais os alunos...ao invés de usar o texto para redação colocar uma história } \\
\text { em quadrinhos...Acho mais interessante fazer em quadrinho porque fico pensando em } \\
\text { criar...tipo...a questão problema conta a estória da indústria que chega à cidade...aí eu } \\
\text { pensei em colocar uma conversa entre habitantes da cidade sobre a chegada dessa } \\
\text { indústria...aí eles questionariam os benefícios, os malefícios. }\end{array}$ \\
\hline
\end{tabular}

Essas pequenas, mas constantes alterações nos planos do licenciando $\mathrm{R}$, mostram sua preocupação e sua inquietação ao elaborar uma sequência que motivasse e instigasse os alunos durante todas as aulas, o que contribuiu, também, para uma evolução nos níveis de AC. O plano 1, por exemplo apresentava competências das dimensões Conteúdo e Contexto, pois o licenciando valorizou demasiadamente o desenvolvimento de conceitos e apresentou limitação na descrição de atividades, como o levantamento de ideias prévias e de elementos relacionados à uma atividade experimental investigativa. Assim, mesmo apresentando algumas questões de alta ordem cognitiva, a limitação no desenvolvimento dos elementos pedagógicos com características investigativas poderia prejudicar o desenvolvimento conceitual e cognitivo dos alunos.

No entanto, conforme os planos vão sendo lapidados, ou seja, no momento em que o licenciando consegue definir seus objetivos, conteúdos, questões e atividade experimental, a sequência apresenta-se mais estruturada e organizada, podendo assim, contribuir para a evolução no nível investigativo, desenvolvimento cognitivo e da AC em dimensões mais elevadas, contemplando, inclusive, as quatro dimensões.

A Figura 2 representa as ideias manifestadas pelo licenciando $\mathrm{R}$ para o último plano proposto, bem como, a relação dessas ideias com a perspectiva norteadora do PRO. A sequência de aula final apresentava sete aulas. 
Figura 2. Esquema representativo das ideias manifestadas por $\mathrm{R}$ em seu último plano

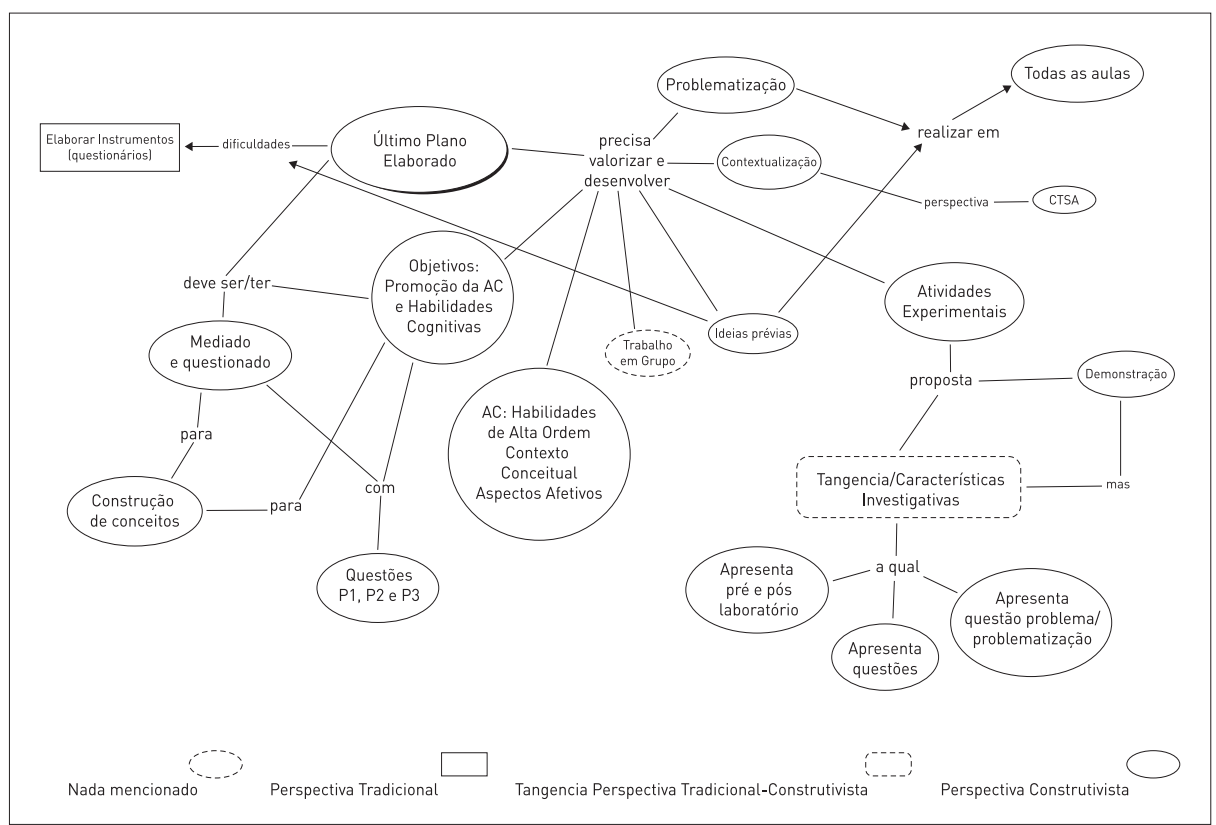

A Figura 2 evidencia uma evolução dolicenciandocom relação às concepções iniciais apresentadas, as quais estavam, na grande maioria, pouco relacionadas à perspectiva norteadora deste PRO. A proposição da questão problema, de um experimento com características investigativas, de contextualização dos conceitos e de habilidades relacionadas às quatro dimensões de AC propostas por Schwartz, evidencia as contribuições do PRO no desenvolvimento dos planos do licenciando.

Uma semana após a proposição do último plano, o licenciando inicia a regência da sequência de sete aulas na escola parceira. Os principais aspectos abordados nas sete aulas estão descritos no Quadro 12.

Quadro 12. Resumo das aulas ministradas pelo licenciando

\begin{tabular}{|c|c|}
\hline Aula & Ideias Abordadas \\
\hline 1 & $\begin{array}{l}\text { Situação problema envolvendo a instalação de uma indústria têxtil próxima ao } \\
\text { principal rio de uma comunidade pesqueira. }\end{array}$ \\
\hline 2 & Obtenção de corantes, naturais e sintéticos e sua importância para a sociedade. \\
\hline 3 & $\begin{array}{l}\text { Realização de um experimento investigativo envolvendo o tratamento da água } \\
\text { contaminada por corantes (tropaeolina, azul de metileno e verde de malaquita), } \\
\text { utilizando como adsorventes a caulinita e o carvão ativado. }\end{array}$ \\
\hline 4 & $\begin{array}{l}\text { Argumentações CTSA e discussões sobre formas de tratamento dos efluentes e } \\
\text { da aplicabilidade e viabilidade dos adsorventes utilizados no processo. }\end{array}$ \\
\hline 5 e 6 & $\begin{array}{l}\text { Explicação sobre os conceitos de polaridade e interações moleculares por meio } \\
\text { de simuladores computacionais }\end{array}$ \\
\hline 7 & $\begin{array}{l}\text { Elaboração, pelos alunos, de um texto argumentativo para solucionar a } \\
\text { problematização inicial. }\end{array}$ \\
\hline
\end{tabular}


0 processo de reflexão orientada na formação inicial de um licenciando de Química visando o ensino por investigação e a promoção da alfabetização científica

A Figura 3 mostra que as aulas ministradas pelo licenciando $R$ apresentaram características norteadoras deste PRO. As aulas contemplaram elementos pedagógicos de um ensino por investigação, como a problematização e ainda o desenvolvimento de habilidades relacionadas às quatro dimensões de AC, ou seja, Conceitual, Contexto, Habilidades de Alta Ordem e Aspectos Afetivos.

Figura 3. Esquema representativo das ideias manifestadas por $R$ durante a regência de aulas

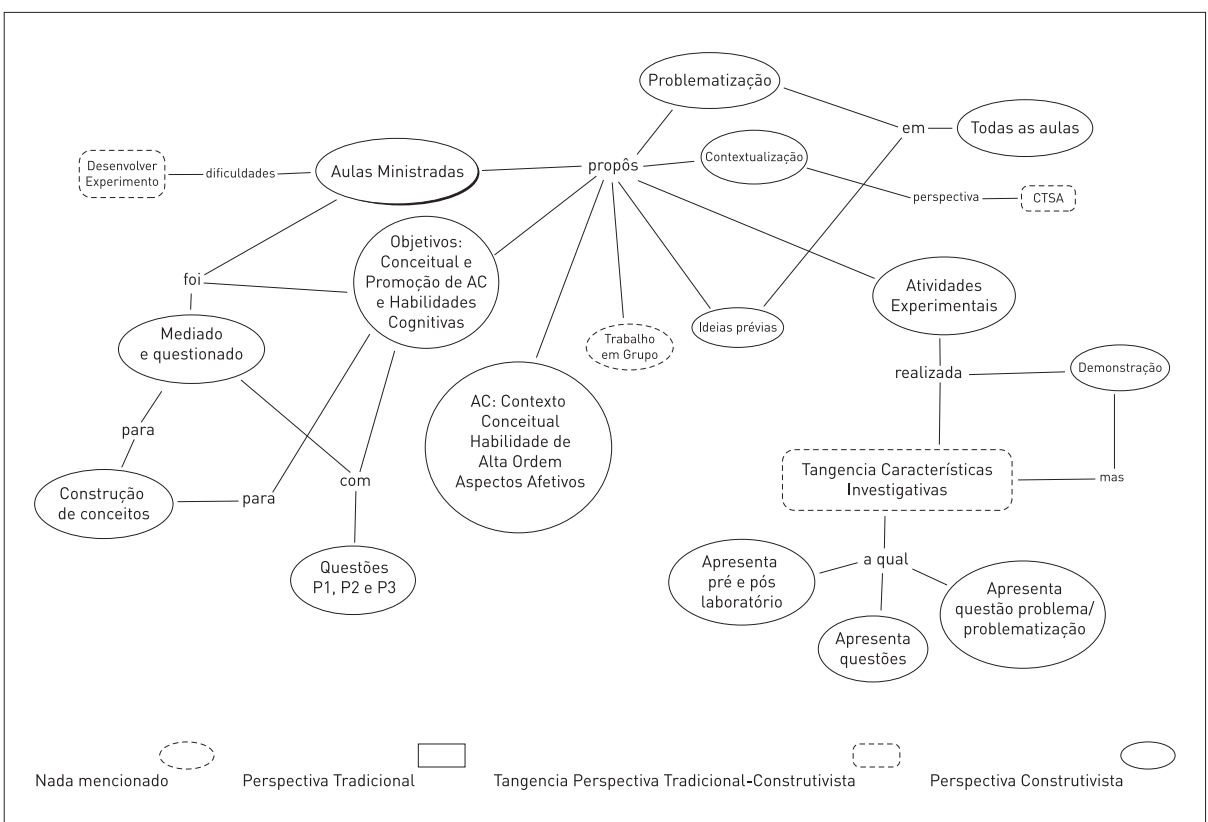

O Quadro 13 mostra os níveis cognitivos, investigativos e as dimensões de AC predominantes em cada aula ministrada por R. Os elementos pedagógicos analisados alcançados por ele apresentam-se, na sua maioria, nos níveis C3 e C4, ou seja, as aulas "apresentam algumas características investigativas" ou "são investigativas". 
Rita de Cássia Suart| Maria Eunice Ribeiro Marcondes

Quadro 13. Síntese dos aspectos analisados nos planos propostos pelo licenciando $R$

\begin{tabular}{|c|c|c|c|}
\hline \multirow[b]{2}{*}{$\begin{array}{l}\text { Aula } \\
\text { referente }\end{array}$} & \multicolumn{3}{|c|}{ Aspecto Investigado } \\
\hline & $\begin{array}{c}\text { Nível } \\
\text { investigativo } \\
\text { predominante }\end{array}$ & $\begin{array}{c}\text { Nível } \\
\text { Cognitivo } \\
\text { predominante }\end{array}$ & Nível/Dimensão predominante de AC \\
\hline Aula 1 & C3 & P1 & $\begin{array}{c}\text { Conteúdo, Contexto, Habilidades Alta Ordem, } \\
\text { Aspectos Afetivos }\end{array}$ \\
\hline Aula 2 & $\mathrm{C} 3$ & P1 e P3 & $\begin{array}{c}\text { Conteúdo, Contexto, Habilidades Alta Ordem, } \\
\text { Aspectos Afetivos }\end{array}$ \\
\hline Aula 3 & C3 & P1, P2 e P3 & Conteúdo, Contexto, Habilidades Alta Ordem \\
\hline Aula 4 & $\mathrm{C} 3$ & P1 e P2 & Conteúdo \\
\hline Aula 5 & $\mathrm{C} 3$ & P1 e P2 & Conteúdo, Contexto, Habilidades Alta Ordem \\
\hline Aula 6 & C3 & P1 e P2 & $\begin{array}{c}\text { Conteúdo, Contexto, Habilidades Alta Ordem, } \\
\text { Aspectos Afetivos }\end{array}$ \\
\hline Aula 7 & $\mathrm{C} 3 / \mathrm{C} 4$ & P1, P2 e P3 & $\begin{array}{c}\text { Conteúdo, Contexto, Habilidades Alta Ordem, } \\
\text { Aspectos Afetivos }\end{array}$ \\
\hline
\end{tabular}

Ao analisar as gravações das aulas, licenciando e pesquisadora observam que em todas as aulas ministradas por ele, foram retomadas discussões acerca da situação problema. Estes momentos são fundamentais no ensino baseado em uma perspectiva por investigação, uma vez que propicia ao aluno refletir e criticar o contexto da situação, possibilitando-o a coletar e comparar dados, elaborar hipóteses e propor inferências para responder ao problema.

O Quadro 14 mostra a reflexão entre eles.

Quadro 14. Reflexão entre Pesquisadora e Licenciando sobre a Questão Problema proposta na regência

\begin{tabular}{|c|c|}
\hline $\mathbf{L}$ & \multicolumn{1}{c|}{ Descrição das falas } \\
\hline $\mathbf{P}$ & Você conseguiu voltar sempre? ((refere-se a questão problema)) \\
\hline $\mathbf{R}$ & $\begin{array}{l}\text { Acho que eu fiz até demais (risos) eu sempre iniciava com ela éh....no questionário } \\
\text { prévio a gente ia discutindo e eu fazia a pergunta logo de cara...eu questionava os } \\
\text { riscos e fiz ela...e aí na primeira aula eu já comecei com ela aí na segunda...aí no início } \\
\text { meio e fim eu estava repetindo a pergunta }\end{array}$ \\
\hline
\end{tabular}

Apenas na quarta aula o licenciando não propõe ou retoma a questão problema de forma bem delineada, o que ocasionou a sua classificação no nível C3. A reflexão entre pesquisadora e licenciando evidencia a análise, transcrita no Quadro 15. 
0 processo de reflexão orientada na formação inicial de um 1icenciando de Química visando o ensino por investigação e a promoção da alfabetização científica

Quadro 15. Reflexão entre Pesquisadora e Licenciando sobre a classificação segundo os níveis

\begin{tabular}{|c|c|}
\hline L & Descrição das falas \\
\hline $\mathbf{P}$ & $\begin{array}{l}\text { A problematização... (pesquisadora lê a descrição dos níveis)... Nessa aula } 4 \text { você } \\
\text { coloca C3. O que aconteceu de diferente aqui? }\end{array}$ \\
\hline $\mathbf{R}$ & $\begin{array}{l}\text { Essa aula não foi focada tanto na questão problema. Foi teórica. Eh...aía gente partiu } \\
\text { da ideia do porquê o experimento aconteceu daquele jeito, mas não voltando na } \\
\text { questão problema. }\end{array}$ \\
\hline $\mathbf{P}$ & E o que você fez de diferente na quinta aula que era teórica também e você colocou $C 4$ ? \\
\hline $\mathbf{R}$ & $\begin{array}{l}\text { A aula } 4 \text { foi a primeira aula teórica...então...assim...eu tentei relembrar a aula anterior } \\
\text { só que essa aula ficou mais direcionada para entender o conhecimento científico... } \\
\text { não ficou como as aulas anteriores, e a seguinte que eu voltei relacionando a questão } \\
\text { problema...essa eu foquei mais no conhecimento científico e os conceitos, então acho } \\
\text { que perdeu um pouco a problematização dessa aula }\end{array}$ \\
\hline $\mathbf{P}$ & E na aula cinco? \\
\hline $\mathbf{R}$ & $\begin{array}{l}\text { Como na quatro o resultado não foi muito... boa a participação e depois que a gente } \\
\text { conversou, eu tentei voltar com questões contextualizadas, retomando as questões } \\
\text { iniciais tentando dar um sentido do porquê eles precisariam saber polaridade...e aí } \\
\text { explicando junto com o experimento...e de eles explicarem de como um adsorvente } \\
\text { adsorve melhor um material que outro... para fechar as ideias }\end{array}$ \\
\hline
\end{tabular}

O trecho extraído do encontro reflexivo mostra a preocupação do licenciando em instigar os estudantes para a resolução do problema proposto. Percebe-se também, pelo trecho destacado em negrito, que o licenciando relata sobre a reflexão realizada entre ele e a pesquisadora durante a sua regência de aulas, quando ele se sentiu incomodado por não ter alcançado o que havia planejado e proposto para a aula, o que, segundo ele, ocasionou em um desvio do foco e desinteresse pelos estudantes. Neste sentido, destacamos as contribuições do processo reflexivo orientado nas ações do futuro professor, já que, com o auxílio da pesquisadora, que atuava como estimuladora e motivadora das ações do professor novato, o licenciando refletiu sobre as suas ações e as sugestões realizadas por ela de forma construtiva.

Assim, o licenciando considera que uma questão mais direcionada ao cotidiano real dos estudantes poderia ter contribuído para um maior envolvimento deles durante a sequência, conforme mostra o trecho transcrito do encontro no Quadro 16.

Quadro 16. Reflexão entre Pesquisadora e Licenciando sobre a reelaboração Questão Problema

\begin{tabular}{|c|l|}
\hline $\mathbf{L}$ & \multicolumn{1}{|c|}{ Descrição das falas } \\
\hline $\mathbf{R}$ & $\begin{array}{l}\text { Talvez se eu tivesse trabalhado com uma situação real com dados reais... em tal } \\
\text { cidade teve tal problema...tem tal rio importante...talvez eles se interessassem mais }\end{array}$ \\
\hline $\mathbf{P}$ & Pode ser.... \\
\hline $\mathbf{R}$ & $\begin{array}{l}\text { Trabalhar... trazer mais coisa desse tipo...colocar propaganda de indústrias...tipo a } \\
\text { gente faz tal tratamento...e analisar se ela faz o tratamento e se é adequado }\end{array}$ \\
\hline
\end{tabular}


Um dos momentos mais conflitantes do PRO para o licenciando R está no desenvolvimento da atividade experimental na terceira aula. $\mathrm{O}$ licenciando expressa as dificuldades encontradas para desenvolver e mediar o experimento em sala de aula, conforme mostra excerto da transcrição do encontro reflexivo no Quadro 17.

Quadro17. Reflexão entre Pesquisadora e Licenciando sobre o experimento ministrado.

\begin{tabular}{|c|c|}
\hline $\mathbf{L}$ & \multicolumn{1}{c|}{ Descrição das falas } \\
\hline \multirow{6}{*}{$\mathbf{R}$} & $\begin{array}{l}\text { A concentração que eu fiz é agitar esperar um pouco e filtrar que perde a cor...só } \\
\text { que esse espaço de colocar o corante mostrar para a turma e você tem que fazer } \\
\text { questões...aí você vai e filtra aí demora um pouquinho aí você pega a solução e vai } \\
\text { mostrar para a turma aí você vai tentando questionar porque perdeu pra ouvir o } \\
\text { pessoal falar...aí vai fazendo isso vê que o tempo, está acabando e corre para fazer } \\
\text { o resto...mas eu consegui fazer as perguntas por que está perdendo...aí eu tentava } \\
\text { perguntar por que você acha que vai acontecer isso. }\end{array}$ \\
\hline
\end{tabular}

A reflexão mostra que o licenciando se sente frustrado e incomodado com sua mediação nessa aula. Ele atribui a sua pouca interatividade durante a execução do experimento à dinâmica das ações, já que exigia que ele realizasse o procedimento, questionasse os estudantes, mostrasse as evidências aos alunos, ou seja, muitas ações que, para ele, eram novas e simultâneas. Realizar experimentos investigativos, bem como controlar as várias situações que ocorrem concomitantemente à sua execução, não são tarefas fáceis para um professor em formação inicial (SILVA, 2015; FRIEDRICHSEN; MUNFORD; ORGILL, 2006).

O final do trecho transcrição anterior mostra que o licenciando refletiu sobre as questões que propunha e a pouca participação dos estudantes durante as aulas. Essas reflexões são constantes nos encontros com a pesquisadora, conforme mostra um trecho de outro encontro reflexivo, transcrito no Quadro 18.

Quadro 18. Reflexão entre Pesquisadora e Licenciando sobre as questões propostas

\begin{tabular}{|c|c|}
\hline $\mathbf{L}$ & Descrição das falas \\
\hline $\mathbf{R}$ & $\begin{array}{l}\text { Essas questões que eu discuti durante a aula... às vezes eu perguntava "Como você } \\
\text { faria isso". aí, tipo, a galera se dispersava pois não sabia como fazer isso...talvez devia } \\
\text { ter me atentado mais com essas questões...não sei se exigi muita coisa deles. }\end{array}$ \\
\hline $\mathbf{P}$ & $\begin{array}{l}\text { A exigência cognitiva... quando você pergunta "como" é uma questão de alta ou baixa } \\
\text { ordem? }\end{array}$ \\
\hline $\mathbf{R}$ & Como? De alta de ordem \\
\hline $\mathbf{P}$ & $\begin{array}{l}\text { Então... pode colocar o como... aí você pode percebe que não vem uma resposta } \\
\text { para o "como"... aí você pode reduzir... ao "que"... o que é uma pergunta que talvez } \\
\text { exija cognitivamente menos...o que vai ser melhor o carvão ou a caulinita... aí você } \\
\text { dá opções... e então você começa...vamos lá... porque adsorveu mais? Ou seja, } \\
\text { você começa diminuindo o nível cognitivo das perguntas... e depois aumenta [..] } \\
\text { trazendo os elementos. }\end{array}$ \\
\hline
\end{tabular}


0 processo de reflexão orientada na formação inicial de um 1icenciando de Química visando o ensino por investigação e a promoção da alfabetização científica

Um dos fatores que podem ter influenciado a ação do licenciando está na ansiedade em cumprir o que estava proposto no planejamento, conforme mostra o trecho da reflexão a seguir, no Quadro 19.

Tal aspecto parece ter interferido no nível cognitivo das questões propostas. Nas aulas 5, 6 e 7, o licenciando realiza um elevado número de questões, as quais foram classificadas, em sua grande maioria, no nível cognitivo P1, evidenciando que ele parecia direcionar o raciocínio dos estudantes para uma resposta que considerava adequada e satisfatória de forma a alcançar os objetivos propostos para sua sequência

Quadro 19. Reflexão entre Pesquisadora e Licenciando sobre a regência

\begin{tabular}{|c|l|}
\hline $\mathbf{L}$ & \multicolumn{1}{c|}{ Descrição das falas } \\
\hline \multirow{2}{*}{$\mathbf{R}$} & $\begin{array}{l}\text { Acho que isso também contribuiu para... acho que eu tentava seguir o planejamento } \\
\text { [...]Durante as aulas também...em cumprir o planejamento eu poderia ter... até mesmo } \\
\text { durante a aula ter mudado alguma coisa...essa fixação de cumprir o planejamento } \\
\text { não... não conseguir voltar algumas coisas... agora eu vi que têm muitas coisas ali que } \\
\text { precisam ser mudadas... tanto que vou ter que reformular essa sequência (risos) e foi } \\
\text { legal assistir as aulas }\end{array}$ \\
\hline
\end{tabular}

Isso mostra as dificuldades de professores novatos conseguirem administrar a multiplicidade de acontecimentos da sala de aula e alcançar uma proposta que apresente características de uma abordagem investigativa e para a promoção da AC (GAUTHIER; 2013; BRICKHOUSE; BODNER, 1992).

No entanto, os resultados mostraram que as aulas do licenciando $\mathrm{R}$ atingiram níveis e dimensões elevados de AC. A primeira e a segunda aula ministrada pelo licenciando, por exemplo, parecem contemplar as dimensões Conteúdo, Contexto e Habilidades de Alta Ordem. Ao levantar as ideias dos estudantes, concepções alternativas e equivocadas sobre a temática foram manifestadas e alguns conceitos apresentam-se limitados, nos fazendo inferir que se tratava de conteúdos memorizados, aspectos da dimensão Conteúdo. Ao mesmo tempo, a situação problema apresentada pelo licenciando, por meio do quadrinho, possibilitou aos estudantes desenvolverem e manifestarem habilidades associadas ao Contexto vivenciado. Ainda, as ações do licenciando podem ter contribuído para o desenvolvimento de Habilidades de Alta Ordem, ao propiciar que os estudantes analisassem os pontos positivos e negativos da instalação da indústria na cidade, bem como, se interessassem mais pelas Ciências diante da temática proposta e do ambiente investigativo desenvolvido, habilidades relacionadas à dimensão Aspectos Afetivos.

As contribuições do PRO também são relatadas pelos licenciando. $\mathrm{O}$ trecho apresentado a seguir no Quadro 20 evidencia que o licenciando reconhece a importância do PRO para sua formação. 
Rita de Cássia Suart| Maria Eunice Ribeiro Marcondes

Quadro 20. Reflexão entre Pesquisadora e Licenciando sobre as contribuiç̃es do PRO

\begin{tabular}{|c|l|}
\hline $\mathbf{L}$ & \multicolumn{1}{c|}{ Descrição das falas } \\
\hline \multirow{6}{*}{$\mathbf{R}$} & $\begin{array}{l}\text { Comecei a gravar ao invés de anotar as minhas ideias... então eu percebi muita } \\
\text { coisa que durante o planejamento eu não tinha ideia [...] Porque só com a reflexão } \\
\text { que eu tive dentro da sala eu acho que não dá para observar todos os detalhes...por } \\
\text { pequeno que seja...só com essa reflexão na sala acho que não dava para ver...agora } \\
\text { vendo detalhado cada aula...tipo...eu assistia um minuto e ficava falando mais um no } \\
\text { gravador...aí eu ia transcrever e ficava pensando um minuto no assunto. }\end{array}$ \\
\hline
\end{tabular}

A sua determinação e a sua persistência durante a participação no PRO, possibilitou a ele atuar ativamente nas ações propostas e se dedicar a uma formação mais reflexiva (ALARCÃO, 2011).

Assim, consideramos que desenvolver atividades e ações de forma interativa com os estudantes, para que eles construam suas próprias ideias, avaliando inferências e dados, parece não ser tarefa fácil para um professor em formação inicial, Nesse sentido, evidenciamos a importância de professores em formação inicial participarem de ações, assim como as vivenciadas pelo licenciando $\mathrm{R}$, ao elaborar seus planejamentos, ministrar suas aulas, bem como, avaliar reflexiva e criticamente suas ações (PEME-ARANEGA et al., 2009).

\section{CONSIDERAC̣̃̃ES FINAIS}

A sequência de aulas proposta e ministrada pelo licenciando $\mathrm{R}$ se aproximou de uma atividade por investigação. Uma justificativa para isso está no fato de ele ter reconhecido a importância da questão problema em atividades dessa natureza desde o início do PRO e sustentado o desenvolvimento desse elemento pedagógico durante toda sua ação em sala em aula.

Apesar das dificuldades iniciais com a proposição de questões, como para o levantamento das ideias prévias e questões de diferentes níveis cognitivos, os estudos teóricos e o processo reflexivo parecem ter contribuído para que ele elaborasse questões dos três níveis cognitivos no último plano e as desenvolvessem em sala de aula, criando um ambiente interativo, que possibilitou a participação dos estudantes.

É importante considerar que, dentre os aspectos manifestados pelo licenciando durante as reflexões sobre os planos elaborados e as aulas ministradas, o desenvolvimento ou promoção da AC foi, talvez, o menos mencionado. Expressões ou relatos relacionados a esse tema foram pouco espontaneamente evidenciados. Ocorreram com maior frequência, quando indagados pela pesquisadora. Embora tenha alcançado diferentes dimensões de AC em suas aulas, a diversidade e multiplicidade de acontecimentos vivenciados durante a regência parecem ter sido mais evidenciadas por ele do que o desenvolvimento da AC. O auxílio da pesquisadora e do grupo para a reflexão sobre a AC alcançada mostrou-se importante, já que o licenciando manifestou ideias e concepções sobre o desenvolvimento da AC em suas aulas apenas após o início das reflexões sobre suas ações, ou seja, depois da regência, evidenciando novamente a importância do PRO na formação reflexiva dos futuros professores. 
0 processo de reflexão orientada na formação inicial de um 1icenciando de Química visando o ensino por investigação e a promoção da alfabetização científica

Neste sentido, embora o licenciando R possa não ter conseguido desenvolver em sala de aula, satisfatoriamente alguns aspectos de sua sequência planejada, ele pode ter direcionado seu olhar para outras situações relacionadas à prática docente, como, levantar a ideias dos estudantes, propor a questão problema, realizar o experimento de maneira investigativa, questionar os estudantes, motivá-los e sensibilizá-los durante as aulas, controlar a disciplina, dominar o conteúdo, falar corretamente, ou seja, uma gama de ações, novas e repletas de incertezas e geradoras de ansiedade e medo, em um ambiente ainda pouco conhecido e dominado por ele.

Um fator de extrema relevância e que deve ser ressaltado refere-se à aplicação da sequência em contexto real de sala de aula, pois permitiu ao licenciando vivenciar as situações reais de ensino, ou seja, lidar com a conversa dos estudantes, com os barulhos externos, com atrasos e interrupções das aulas, com a resistência dos estudantes em participar das aulas ou aceitar novas propostas, entre outras.

Outro aspecto bastante importante a ser considerado está na necessidade de individualizar a formação do professor, considerando suas características pessoais e sociais, já que o PRO incide de maneira bastante diferente nos professores ou futuros professores, podendo variar, entre outros fatores, de acordo com a formação ambiental vivenciada e com o conhecimento do conteúdo, o conceitual e o pedagógico (PEME-ARANEGA et al., 2009). Isso evidencia a importância dos momentos proporcionados pelos encontros individuais neste PRO, já que a pesquisadora pôde priorizar as necessidades, as dificuldades, os dilemas e os anseios de cada licenciando. Ao mesmo tempo, o PRO mostra a necessidade urgente de mudanças nos cursos de formação, que consideram estar proporcionando uma boa formação agrupando uma ou mais dezenas de estudantes nas salas de aulas das Licenciaturas ou das escolas campos de estágio.

Contudo, o tempo e a dedicação demandados pelos envolvidos, podem ser utilizados como argumentos contrários ao desenvolvimento de ações similares às propostas neste $\mathrm{PRO}$. No entanto, tais ações podem ser realizadas por meio da interface entre as disciplinas Estágio Supervisionado e Práticas Como Componente Curricular, de forma a fortalecer a relação teoria-prática-reflexão.

Ressalta-se ainda, o papel do mediador em um PRO, o qual deve desempenhar um papel de apoio, ao contrário de avaliativo ou impositivo. Os professores em formação inicial precisam de um formador com quem possam discutir e refletir, abertamente e sem receios. Assim, neste PRO, todas as decisões foram tomadas pelo licenciado $\mathrm{R}$ após reflexões sucessivas com a pesquisadora. Em nenhum momento ela atuava de forma autoritária. Pelo contrário, ela apontava os aspectos que considerava relevantes para o alcance de uma proposta de ensino por investigação e para a promoção da AC e o professor em formação inicial tinha a liberdade para fazer as suas escolhas, as quais seriam novamente refletidas durante o PRO. Assim, podemos inferir que o licenciando evolui em suas concepções e crenças durante o processo de forma orientada, mas autônoma.

Assim, reforçamos a importância das ações desenvolvidas neste PRO, desde a formação inicial dos licenciandos, para que os futuros professores possam manifestar e confrontar suas ideias e crenças, seus dilemas e conflitos, participando de ações e atividades que deem a eles a oportunidade de desenvolverem práticas docentes que estejam relacionadas às atuais perspectivas de ensino e aprendizagem, como a proposta desta pesquisa, ou seja, atividades investigativas e para a promoção da AC. 


\section{REFERÊNCIAS}

ABELL, S. K.; BRYAN, L. A. Reconceptualizing the elementary science methods course using a reflection orientation. Journal of Science Teacher Education, Netherlands, v. 8, n. 3, p. 153-166, 1997.

ALARCÃO, I. Professores reflexivos em uma escola reflexiva. $8^{a}$ edição. São Paulo: Editora Cortez, 110 p., 2011.

AZEVEDO M. C. P. S. Ensino por Investigação: Problematizando as atividades em sala de aula. In: CARVAlHO, A. M. P. (org.), Ensino de Ciências: Unindo a Pesquisa e a Prática. São Paulo: Thomson, cap. 2, p. 19-33, 2004.

BYBEE, R. W. Scientific inquiry and nature of science: implications for teaching, learning and teacher education. Springer, 2006.

BOGDAN, R. C.; BIKLEN, S. K. Investigação qualitativa em educação: uma introdução à teoria e aos métodos. Trad. Maria João Alvarez. Portugal, Porto Editora, 355p., 1994.

BRICKHOUSE, N.; BODNER, G. M. The beginning science teacher: Classroom narratives of convictions and constraints. Journal of Research in Science Teaching, v. 29, p. 471-485, 1992.

BRYAN, L.A.; RECESSO, A. Promoting Reflection among Science Student Teachers using a WEBbased video analysis tool. Journal of Computing in Teacher Education, v. 23, p. 31-39, 2006.

CARVALHO, A. M. P. Las practices experimentales en el proceso de enculturación cientifica. In: GATICA, M. Q.; ADÚRIZ-BRAVO, A. (Ed). Enseñar ciencias en el Nuevo milenio: retos e propuestas. Santiago: UCC, p.73-90, 2006.

CHAMIZO, J. A.; HERNÁNDEZ, G. Construcción de preguntas, la Ve epistemológica y examen ecléctico. Educación Química, v. 11, p. 182-187, 2000.

CHASSOT, A. Alfabetização científica: uma possibilidade para a inclusão social. Revista Brasileira de Educação, p. 89-100, 2003.

FRIEDRICHSEN, P.; D. MUNFORD; ORGILL, M. Brokering at Boundary: A Prospective Science Teacher Engages Students in Inquiry. Science Education, v. 90, n. 3, p. 522-543, 2006.

GAUTHIER, C.; MARTINEAU, S.; DESBIENS, J. F.; MALO, A.; SIMARD, D. Por uma teoria da Pedagogia. Pesquisas Contemporâneas sobre o Saber Docente. Tradução de Francisco Pereira

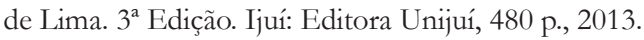

GHEDIN, E. Professor reflexivo: da alienação da técnica à autonomia da crítica. In: PIMENTA, S. G.; GHEDIN, E. (org.). Professor reflexivo no Brasil: Gênese e crítica de um conceito. $7^{a}$ ed. São Paulo: Cortez, p. 148-173, 2012.

GOMES, A. D. T.; BORGES, A.T.; JUSTI, R. Processos e Conhecimentos envolvidos na realização de atividades práticas: revisão da literatura e implicações para a pesquisa. Investigações em Ensino de Ciências, v.13, n. 2, p.187-207, 2008.

KASSEBOEHMER, A. C.; FERREIRA, L. H. O espaço da prática de ensino e do estágio curricular nos cursos de formação de professores de Química das IES públicas paulistas. Química Nova, v. 31, n. 3, p. 694-699, 2008. 
0 processo de reflexão orientada na formação inicial de um 1icenciando de Química visando o ensino por investigação e a promoção da alfabetização científica

LANGUI, R.; NARDI, R. Interpretando reflexões de futuros professores de física sobre sua prática profissional durante a formação inicial: a busca pela construção da autonomia docente. IENCI, v. 16, n. 3, p. 403-424, 2011.

MALDANER, O. A. A pós-graduação e a formação do educador químico. In: ROSA, M. I. P.; ROSSI, A.V. Educação Química: memórias, tendências, políticas. Campinas: Átomo, p. 269-288, 2008.

MELLADO, V. The classroom practice of preservice teachers and their conceptions of teaching and learning science. Science Education, v. 82, p. 97-214, 1998.

NORRIS, S.P.; PHILLIPS, L.M. How Literacy in Its Fundamental Sense is Central to Scientific Literacy. Science Education, v. 87, n. 2, p. 224-240, 2003.

PEME-ARANEGA, C.; MELlADO, V.; DE LONGUI, A. L.; MORENO, A.; RUIZ, C. La interacción entre concepciones y la práctica de uma profesora de Física de nível secundário: Estudio longitudinal de desarrollo profesional basado em el proceso de reflexión orientada colaborativa. Revista de Enseñanza de las Ciencias, v. 8, n. 1, p. 283-303, 2009.

SASSERON, L. H.; CARVALHO, A. M. P. de. Alfabetização Científica: uma revisão bibliográfica. Investigações em Ensino de Ciências, v. 16, p. 59-77, 2011.

SHWARTZ, Y. Chemical Literacy. Defining it with teachers and assessing its expression at the high-school level. Germany: Lambert, 201 p., 2009.

SILVA, A. F. A. Processo de Reflexão Orientada na Formação de Professores dos Anos Iniciais: Concepções e Práticas sobre o Ensino de Ciências. 2015. 338 p. Tese (Doutorado em Ensino de Ciências - Área de concentração Química) - Instituto de Física, Instituto de Química, Instituto de Biociências, Faculdade de Educação, Universidade de São Paulo, São Paulo, 2015.

SILVA, D. P. Questões propostas no planejamento de atividades experimentais de natureza investigativa no ensino de química: reflexões de um grupo de professores. 2011. $212 \mathrm{f}$. Dissertação (Mestrado em Ensino de Ciências) - Faculdades de educação, Universidade de São Paulo, São Paulo, 2011.

SILVA, R. M. G. da; SCHNETZLER, R. P. Concepções e ações de formadores de professores de Química sobre o estágio supervisionado: propostas brasileiras e portuguesas. Química Nova, v.31, n. 8 , p. 2174-2183, 2008.

ZOLLER, U.; DORI, Y.; LUBEZKY, A. Algorithmic and LOCS and HOCS (Chemistry) Exam Questions: Performance and Attitudes of College Students. International Journal of Science Education, v. 24, n. 2, p. 185-203, 2002.

ZÔMPERO, A. F.; LABURÚ, C. E. Implementação de atividades investigativas na disciplina de ciências em escola pública: uma experiência didática. Investigações em Ensino de Ciências, v. 17, n.3, p. 675-684, 2012.

\section{NOTAS}

${ }^{1}$ Nesta pesquisa foram utilizados alguns dos elementos pedagógicos proposto por SILVA. A proposta completa pode ser obtida consultando o trabalho da autora. 


\section{Submetido em 07/11/2017}

Aprovado em 25/01/2018

\section{Contato:}

Universidade Federal de Lavras

Departamento de Química - Campus da UFLA

Caixa Postal 3037 - Lavras, MG - Brasil

CEP $37200-000$ 